\title{
Commentary: The Long History of Vitamin C: From Prevention of the Common Cold to Potential Aid in the Treatment of COVID-19
}

\author{
Harri Hemilä ${ }^{1 * t}$ and Elizabeth Chalker ${ }^{2 \dagger}$ \\ 1 Department of Public Health, University of Helsinki, Helsinki, Finland, ${ }^{2}$ School of Public Health, University of Sydney, \\ Sydney, NSW, Australia
}

\section{OPEN ACCESS}

Edited by:

Philip Calder,

University of Southampton,

United Kingdom

Reviewed by:

Adrian Friedrich

Gombart, Oregon State University,

United States

*Correspondence:

Harri Hemilä

harri.hemila@helsinki.fi

tORCID:

Harri Hemilä

orcid.org/0000-0002-4710-307X

Elizabeth Chalker

orcid.org/0000-0003-1593-3770

Specialty section: This article was submitted to Nutritional Immunology, a section of the journal

Frontiers in Immunology

Received: 26 January 2021 Accepted: 10 March 2021

Published: 01 April 2021

Citation:

Hemilä H and Chalker E (2021) Commentary: The Long History of

Vitamin C: From Prevention of the Common Cold to Potential Aid in the

Treatment of COVID-19.

Front. Immunol. 12:659001. doi: 10.3389/fimmu.2021.659001
Keywords: ascorbic acid, common cold, coronavirus, immune system, pneumonia, respiratory tract infections, rhinovirus

\section{A Commentary on}

The Long History of Vitamin C: From Prevention of the Common Cold to Potential Aid in the Treatment of COVID-19

by Cerullo G, Negro M, Parimbelli M, Pecoraro M, Perna S, Liguori G, Rondanelli M, Cena H, D’Antona G. Front Immunol (2020) 11:574029. doi: 10.3389/fimmu.2020.574029

\section{INTRODUCTION}

A review of the effects of vitamin $\mathrm{C}$ on the immune system and respiratory tract infections was recently published (1). We are the authors of a review of vitamin C and the common cold (2), which was cited in the article. We consider that some of the authors' statements are inaccurate and here we describe the issues on which we disagree.

\section{STATEMENTS ON VITAMIN C AND THE COMMON COLD}

Cerullo stated "According to Pauling, a daily vitamin C intake of 1,000 mg can reduce the incidence of colds by about $45 \%(3,4)$. However, other clinical studies with similar aims failed to demonstrate its efficacy [(5-8); references renumbered]". The cited references do not support the last statement.

The large Anderson (1972) trial (5) did not fail to demonstrate the efficacy of vitamin C. In contrast, the abstract summarizes the findings as follows "there was a statistically significant difference $(P<0.05)$ between the two groups in the number of subjects who remained free of illness throughout the study period. Furthermore the subjects receiving the vitamin experienced approximately $30 \%$ fewer total days of disability (confined to the house or off work) than those receiving the placebo, and this difference was statistically highly significant $(P<0.001)$ " (5); see Table 1. This does not support the claimed inefficacy of vitamin C.

Karlowski et al. (1975) stated "the effects [of vitamin C] demonstrated might be explained equally well by a break in the double blind" (6). However, Hemilä showed that the statistical analysis in the Karlowski trial was flawed. The reanalysis concluded that "The most important conclusions from 
TABLE 1 | Effect of vitamin C on the proportion of participants with illness in the large Anderson (5) trial.

\begin{tabular}{|c|c|c|c|c|}
\hline \multirow[t]{2}{*}{ Outcome } & \multicolumn{2}{|c|}{ Intervention } & \multirow[t]{2}{*}{ Effect of vitamin C $(95 \% \mathrm{Cl})$} & \multirow[t]{2}{*}{ P (2-tail) } \\
\hline & Vitamin C & Placebo & & \\
\hline No days confined indoors & 232/407 (57\%) & $195 / 411(47 \%)$ & $9.6(2.7,17) \mathrm{pp}$ & 0.006 \\
\hline No days off work & $275 / 407(67 \%$ & $243 / 411(59 \%)$ & $8.4(1.8,15) \mathrm{pp}$ & 0.012 \\
\hline No days with nose or throat symptoms & $131 / 407$ (32\%) & $101 / 411(25 \%)$ & $7.6(1.4,14) \mathrm{pp}$ & 0.016 \\
\hline Free of any illness during the trial & $105 / 407$ (26\%) & $76 / 411(18 \%)$ & $7.3(1.6,13) \mathrm{pp}$ & 0.012 \\
\hline
\end{tabular}

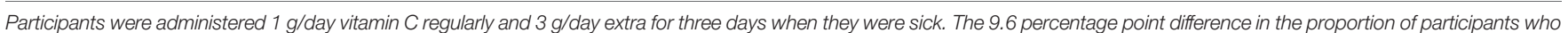

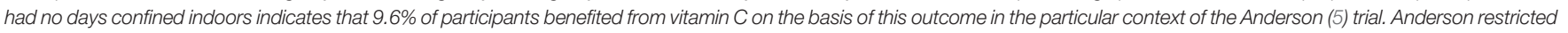

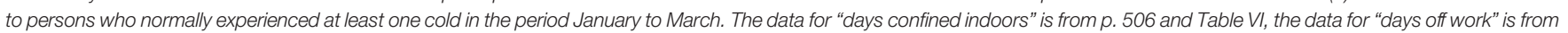

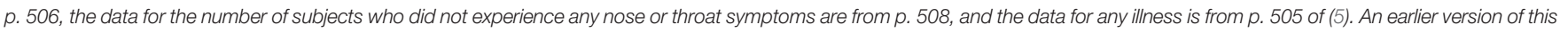
table was published as Table 20 in ref. (9). The calculations were done with the prop.test program of the R package.

pp, percentage point difference in the outcome between the two groups.

Karlowski's study are that therapeutic vitamin C supplementation during a common cold episode appears to be as effective as regular supplementation, and that there appears to be linear dose dependency at least up to $6 \mathrm{~g} /$ day. These findings suggest that large therapeutic vitamin $C$ doses might alleviate the symptoms of the common cold substantially" (9-11).

The Chalmers meta-analysis (1975) calculated that vitamin C shortens common cold duration just by 0.11 (0.24 SE) days (7). However, there were numerous errors in Chalmers' calculations which when corrected led to an estimated reduction in cold duration of $0.93(0.22 \mathrm{SE})$ days $(9,12,13)$. This finding is significant statistically and clinically.

The Dykes and Meier review (1975) (8), also contained substantial errors as detailed previously $(9,13)$.

Cerullo also writes "Vorilhon et al. (14), analyzed eight RCTs and confirmed that vitamin C supplementation ... is not effective, compared to placebo, in reducing the incidence of upper respiratory tract infections (URTI) in 3,135 children..., although the administration can reduce the duration of URTI by $14 \%$ ". However, we showed that the Vorilhon metaanalysis contained errors (15). Thus, the quoted figures are not correct.

Cerullo further writes "Kim et al. (16) carried out a large randomized, double-blind, placebo-controlled trial in 1,444 Korean soldiers, 695 of whom received vitamin C (6 g/day) for 30 days. They showed that the vitamin $\mathrm{C}$ group had a 0.80 -fold lower risk of getting the common cold compared to the placebo group $(\mathrm{n}=749)$." The " 0.80 -fold lower risk" implies that there was a $20 \%$ reduction in the risk, however, 0.80 is the odds ratio which is inappropriate for common outcomes such as the common cold (17). The correct risk reduction for catching a cold was just $8.4 \%$ (18). Further problems are described elsewhere (18).

\section{STATEMENTS ON VITAMIN C AND OTHER MEDICAL CONDITIONS}

The review by Cerullo et al. is also misleading on issues other than the common cold. With respect to vitamin $\mathrm{C}$ and pneumonia, they cite the Padhani (2020) meta-analysis (19) as follows "the most recent meta-analysis including 2,774 participants from seven clinical studies, underlined that current evidence is insufficient to sustain the efficacy of vitamin $C$ supplementation in preventing or treating pneumonia, due to the small number of trials and very low quality of the existing results (19)."

The Padhani review also contains significant errors. We described several of these including the inclusion and exclusion of trials and the statistical calculations (20).

As to the effect of vitamin $\mathrm{C}$ on the mortality of ICU patients, Cerullo referred to the CITRIS-ALI trial as follows: "findings from the CITRIS-ALI study (21) showed a reduced mortality at day 28 in the vitamin C group (29.8\%) compared to the placebo group (46.3\%)". Although the figures are correct, the CITRISALI trial authors flagged concerns with multiple comparisons, which is not mentioned by Cerullo. That said, the multiple comparisons interpretation has been challenged (22). Furthermore, there was a significant difference between the vitamin $\mathrm{C}$ and placebo groups during the 4 -day vitamin $\mathrm{C}$ supplementation period as mortality was decreased by $81 \%$ (95\% CI $45 \%$ to $94 \%$ ), whereas no difference between trial groups was seen after vitamin $\mathrm{C}$ administration was discontinued (22).

\section{DISCUSSION}

Our meta-analysis on vitamin $\mathrm{C}$ and the common cold found that vitamin $\mathrm{C}$ did not decrease the average number of colds in general community trials (2). However, we found that in five trials with 598 physically active participants vitamin C decreased common cold risk by $52 \%$ ( $\mathrm{P}<0.00001)(2)$, yet this effect was not mentioned by Cerullo (1). Furthermore, in one of the largest trials to date, Anderson (1972) (5) found that the occurrence of outcomes "not confined to the house", "not off work", and "not ill during the trial" because of common cold related symptoms were all about 8 percentage points lower in the vitamin $\mathrm{C}$ group than in the placebo group (Table 1). This means that 1 in every 12 participants in the trial benefited from vitamin $\mathrm{C}$.

Vitamin $\mathrm{C}$ is known to cure scurvy, but it may also have an effect on other conditions $(2,4,5,9-13,21,22)$. We consider that some parts of the Cerullo review did not adequately describe the reported effects of the vitamin. There has been much discussion over decades about vitamin $\mathrm{C}$, unfortunately much of it 
erroneous. Solid evidence is required to determine whether vitamin $C$, which is cheap and safe, is effective against other conditions, without the bias that has often been caused by selfperpetuating errors.

\section{REFERENCES}

1. Cerullo G, Negro M, Parimbelli M, Pecoraro M, Perna S, Liguori G, et al. The long history of vitamin $\mathrm{C}$ : from prevention of the common cold to potential aid in the treatment of COVID-19. Front Immunol (2020) 11:574029. doi: 10.3389/fimmu.2020.574029

2. Hemilä H, Chalker E. Vitamin C for preventing and treating the common cold. Cochrane Database Syst Rev (2013) 2013:CD000980. doi: 10.1002/ 14651858.CD000980.pub4. https://hdl.handle.net/10138/225864.

3. Pauling L. Evolution and the need for ascorbic acid. Proc Natl Acad Sci U S A (1970) 67:1643-8. doi: 10.1073/pnas.67.4.1643

4. Pauling L. The significance of the evidence about ascorbic acid and the common cold. Proc Natl Acad Sci USA (1971) 68:2678-81. doi: 10.1073/ pnas.68.11.2678

5. Anderson TW, Reid DB, Beaton GH. Vitamin C and the common cold: a double-blind trial. Can Med Assoc J (1972) 107:503-8.

6. Karlowski TR, Chalmers TC, Frenkel LD, Kapikian AZ, Lewis TL, Lynch JM. Ascorbic acid for the common cold: a prophylactic and therapeutic trial. JAMA (1975) 231:1038-42. doi: 10.1001/jama.1975.03240220018013

7. Chalmers TC. Effects of ascorbic acid on the common cold. An evaluation of the evidence. Am J Med (1975) 58:532-6. doi: 10.1016/0002-9343(75)90127-8

8. Dykes MHM, Meier P. Ascorbic acid and the common cold: evaluation of its efficacy and toxicity. JAMA (1975) 231:1073-9. doi: 10.1001/ jama.1975.03240220051025

9. Hemilä H. Do Vitamins C and E Affect Respiratory Infections? Ph.D. Thesis University of Helsinki, Helsinki, Finland (2006) p. 21-7,36-8,42-5. Available at: https://hdl.handle.net/10138/20335.

10. Hemilä H. Vitamin C, the placebo effect, and the common cold: a case study of how preconceptions influence the analysis of results. J Clin Epidemiol (1996) 49:1079-84. doi: 10.1016/0895-4356(96)00189-8

11. Hemilä H. To the dissent by Thomas Chalmers. J Clin Epidemiol (1996) 49:1087. doi: 10.1016/0895-4356(96)00191-6

12. Hemilä H, Herman ZS. Vitamin C and the common cold: a retrospective analysis of Chalmers' review. J Am Coll Nutr (1995) 14:116-23. doi: 10.1080/ 07315724.1995.10718483

13. Hemilä H. Vitamin C supplementation and common cold symptoms: problems with inaccurate reviews. Nutrition (1996) 12:804-9. doi: 10.1016/ S0899-9007(96)00223-7

14. Vorilhon P, Arpajou B, Vaillant Roussel H, Merlin É, Pereira B, Cabaillot A. Efficacy of vitamin $\mathrm{C}$ for the prevention and treatment of upper respiratory

\section{AUTHOR CONTRIBUTIONS}

All authors contributed to the article and approved the submitted version.

tract infection. A meta-analysis in children. Eur J Clin Pharmacol (2019) 75:303-11. doi: 10.1007/s00228-018-2601-7

15. Hemilä $H$, Chalker E. Meta-analysis on vitamin $C$ and the common cold in children may be misleading. Eur J Clin Pharmacol (2019) 75:1747-8. doi: 10.1007/s00228-019-02733-x

16. Kim TK, Lim HR, Byun JS. Vitamin C supplementation reduces the odds of developing a common cold in Republic of Korea Army recruits: randomised controlled trial. BMJ Mil Heal (2020) bmjmilitary-2019-001384. doi: 10.1136/ bmjmilitary-2019-001384

17. Altman DG, Deeks JJ, Sackett DL. Odds ratios should be avoided when events are common. BMJ (1998) 317:1318. doi: 10.1136/bmj.317.7168.1318

18. Hemilä H. Statistical problems in the vitamin $\mathrm{C}$ and common cold trial with South Korean army recruits. BMJ Mil Heal (2020). Available at: https:// militaryhealth.bmj.com/content/early/2020/03/05/bmjmilitary-2019-001384. responses.

19. Padhani Z, Moazzam Z, Ashraf A, Bilal H, Salam R, Das J, et al. Vitamin C supplementation for prevention and treatment of pneumonia. Cochrane Database Syst Rev (2020) 4:CD013134. doi: 10.1002/14651858.CD013134.pub2

20. Hemilä H, Chalker E. Commentary: Vitamin C supplementation for prevention and treatment of pneumonia. Front Med (2021) 7:595988. doi: $10.3389 /$ fmed.2020.595988

21. Fowler AA, Truwit JD, Hite RD, Morris PE, Dewilde C, Priday A, et al. Effect of vitamin $\mathrm{C}$ infusion on organ failure and biomarkers of inflammation and vascular injury in patients with sepsis and severe acute respiratory failure: the CITRIS-ALI randomized clinical trial. JAMA (2019) 322:1261-70. doi: 10.1001/jama.2019.11825

22. Hemilä H, Chalker E. Reanalysis of the effect of vitamin C on mortality in the CITRIS-ALI trial: important findings dismissed in the trial report. Front Med (2020) 7:590853. doi: 10.3389/fmed.2020.590853

Conflict of Interest: The authors declare that the research was conducted in the absence of any commercial or financial relationships that could be construed as a potential conflict of interest.

Copyright (c) 2021 Hemilä and Chalker. This is an open-access article distributed under the terms of the Creative Commons Attribution License (CC BY). The use, distribution or reproduction in other forums is permitted, provided the original author(s) and the copyright owner(s) are credited and that the original publication in this journal is cited, in accordance with accepted academic practice. No use, distribution or reproduction is permitted which does not comply with these terms. 